\title{
Coleccionismo real y coleccionismo de mercader en la España de Felipe IV
}

\author{
Royal collecting and mercater collecting in the Spain of Philip IV
}

\author{
Santiago Acosta Martínez \\ Universidad Externado de Colombia \\ santiago.acosta01@est.uexternado.edu.co
}

Fecha de recepción: 14 de agosto de 2019

Fecha de aprobación: 21 de diciembre de 2019

\section{Resumen}

A partir de la historia del coleccionismo de Arte en España, se realiza un análisis comparativo entre dos colecciones reconocidas del siglo XVII: el Gabinete de Curiosidades de Cornelis Van Deer Geest (representado por Willem Van Haecht, pintura abordada por medio de un análisis iconográfico e iconológico) y la colección de Felipe IV del Alcázar de Madrid (plasmada en el inventario de 1636 y complementada con el tratado de arte "Diálogos con la Pintura" del artista Vicente Carducho, vigente en aquel entonces), desarrollando el debate sobre la intencionalidad "hacia adentro" o "hacia afuera" de cada tipo de colección, lo discursos reproducidos por estas, y poniendo especial atención a los factores históricos, sociales y culturales que propiciaron estas diferencias. En la primera parte se hace un breve Estado del Arte sobre la historia del coleccionismo de arte en Europa problematizando los conceptos de colección "pública" o "privada". Luego se aborda por separado cada caso realizando las comparaciones propuestas.

Palabras clave: Coleccionismo, intencionalidad, discurso, humanismo.

\begin{abstract}
From the history of art collecting in Spain, a comparative analysis is carried out between two recognized collections of the seventeenth century: the Cabinet of Curiosities of Cornelis Van Deer Geest (represented by Willem Van Haecht, painting analyzed by means of an iconographic and iconological analysis) and the collection of Felipe IV of the Alcazar of Madrid (embodied in the inventory of 1636 and complemented with the art treatise "Dialogues with Painting" by the artist Vicente Carducho, in force at the time), developing the debate about intentionality "inwards" or "outwards" of each type of collection, the discourses reproduced by them, and paying special attention to the historical, social and cultural factors that led to these differences. In the first part there is a brief State of the Art about the history of art collecting in Europe problematizing the concepts of "public" or "private" collection. Then, each case is then dealt with separately making the proposed comparisons.
\end{abstract}

Keywords: Collecting, intentionality, discourse, humanismo. 
El siglo XVII, el Siglo de Oro Español, y en general en Renacimiento europeo, debe su esplendor al alto nivel artístico y cultural. Parece haber sido una época sin parangón en toda la historia de la monarquía, de manera que una de las formas más eficaces de acercarse a este siglo, a la España del XVII, es por medio del arte. Para esta época eran comunes y populares las colecciones de arte. El coleccionismo, que se desarrollaba tanto en las esferas cortesanas como en las aristocráticas o burguesas, e incluso en los palacios reales, era una muestra de la pomposidad del Siglo de Oro, pero, además, de la importancia que tenía el arte para esta época.

Pero, más allá de señalar lo obvio, nosotros nos hemos formulado una pregunta diferente: ¿cómo se coleccionaba? A partir de los trabajos existentes sobre el coleccionismo español del Siglo de Oro, hemos realizado la comparación entre el coleccionismo real y el coleccionismo "de mercader", centrándonos en el triple carácter de lo público-privado, cuyo debate es el argumento principal de este texto, trabajando dos casos específicos: en primer lugar, el Gabinete de Curiosidades de Cornelis Van Deer Geest, retratado por Willem Van Haecht en $1621^{1}$, por medio de un análisis preiconográfico, iconográfico e iconológico, que nos permitirá encontrar ciertos universos de sentido o de significado que existieron en el recinto del mercader; en segundo lugar, la colección de Felipe IV en el Alcázar de Madrid, plasmada en el inventario realizado en $1636^{2}$. A continuación, el lector encontrará una primera sección que se ocupa de desarrollar el debate sobre el carácter público o privado de la colección, definiendo así el elemento a comparar en cada caso, para luego ocuparse de cada caso por separado, identificando y analizando los elementos que se debaten entre una colección "hacia adentro" o "hacia afuera". Por último, en las conclusiones se retoman y se juntan las diferencias y similitudes de cada caso de estudio.

\section{Debates sobre el carácter de lo privado y lo público}

La historia del coleccionismo de arte está bien documentada y la retomaremos en este trabajo a medida que vaya siendo necesario. Pero en ninguno de los trabajos consultados se ha trabajado la diferenciación entre el coleccionismo real y el coleccionismo "privado". Debemos empezar aclarando que, mientras el coleccionismo regio es un concepto claro referente a las colecciones reales de los monarcas ubicados en los palacios reales y continuados o alimentados por sus sucesores, el término "coleccionismo privado" es problemático en sí mismo, porque no denota la clase o el grupo social al

1 Willem Van Haecht, Gabinete de curiosidades de Cornelis van der Geest durante la visita de los archiduques, 1628, óleo sobre tabla, $100 \times 130 \mathrm{~cm}$, Amberes, Casa Rubens. Actualmente la pintura original se encuentra en el Real Instituto de Patrimonio de Arte (KIK) en Bruselas, en proceso de restauración.

2 Museo del Prado, "Inventario del Alcázar de Madrid de 1636", en Inventarios reales: Real Museo (1834); Palacio de San Ildefonso (1814); Palacio del Real Sitio de Aranjuez (1818); Real Palacio de Madrid (1814), Vol. 12. Disponible en: https://www.museodelprado.es/aprende/biblioteca/biblioteca-digital/fondo/ inventarios-reales-v12-real-museo-1834-palacio-de/3e5218fb-3639-432b-be13-9a7295423901. 
que pertenece la colección, sino que hace referencia a una característica que puede ser perfectamente transversal a todo tipo de coleccionismos: no está hecho para la exhibición. El coleccionismo privado tiene un carácter íntimo que se ha venido transformando a lo largo de la historia y que puede rastrearse incluso hasta la antigüedad griega. En contraposición al "museión", que estaba marcado por un "carácter vitalista con el que se concibe este primer museo de la cultura helenística, que responde a un espíritu que hoy denominaríamos universitario, un centro libre para la enseñanza y el intercambio de ideas y conocimientos", tumbas y los templos que, por su lado, estaban llenos de lo que denominaremos "tesoros", es decir, objetos invaluables, de incalculable valor, que constituían un botín. Eran ofrendas a los dioses o propiedad del difunto, y estaban allí con el objetivo de ser valiosos en sí mismos, pero ello no les daba un carácter privado, sino que en realidad estaban a la vista de toda la comunidad para mostrar el esplendor del tesoro.

Esta idea perduró a lo largo del tiempo hasta llegar a los tesoros medievales y sus recintos. Las cámaras de los tesoros normalmente estaban asociadas a aquellos lugares en donde se guardaban reliquias sagradas, y ahora, a diferencia de la antigüedad griega, el tesoro se vuelve privado y misterioso, cuando antes estaba a contemplación de cualquiera que lo visitara, y de alguna manera puede afirmarse que eran riquezas de toda la comunidad. El cristianismo cubre con un aura de divinidad al tesoro guardado con recelo, le otorga cualidades tan elevadas que deben ser custodiados, y por esto poco a poco va desapareciendo su característica pública. "Estos objetos no se coleccionaban, sino que se atesoraban, estaban rodeados de gran misterio, solemnidad y reverencia, y los fieles no tenían acceso a estos"4. Los objetos aquí custodiados no solo son valiosos económica y políticamente, sino que tienen la capacidad de generar sentimientos de adoración en quienes los poseen (y aún más en quienes no pueden hacerlo, alimentados por el misterio).

Sin embargo, estas cámaras del tesoro pronto encontrarán un camino paralelo al religioso, y no habría demora en el surgimiento de cámaras del tesoro "profanas" propias de los príncipes de la Alta Edad Media. Si el templo griego presentaba tesoros públicos y de todos los integrantes de la comunidad, y las iglesias medievales los llenaban de misterio y divinidad y los alejaban del público, esto último no implica necesariamente un carácter privado del tesoro (es de la iglesia, de la comunidad cristiana, aunque los fieles no tengan acceso a él). La versión profana y principesca de las cámaras de los tesoros (como, por ejemplo, la Francia de los Valois) hacen hincapié en un nuevo carácter exclusivamente privado de lo atesorado. Ahora, esto no quiere decir que el tesoro no estuviera también proyectado hacia afuera, o que de su existencia únicamente la supiera su propietario. Aunque nadie tuviera acceso al tesoro, los

3 Serrano, La formación histórica, 2.

4 Morán y Checa, El coleccionismo en España. 
Valois eran famosos en toda Europa por la riqueza que atesoraban en los salones de sus palacios. Este tesoro es privado, es íntimo e inaccesible, pero cumplía una función de estatus social material. "La cámara del tesoro es, como ya se ha dicho, la proyección hacia el exterior, desde lo agitado a lo sosegado, de este concepto primitivamente ingenuo de propiedad entendida como adorno" ". El concepto de tesoro, entonces, gira en torno a la simple ostentación de bienes valiosos por sí mismos, lo cual habla sobre su dueño tan sólo en la medida en que lo menciona como capaz de custodiarlo. La función del tesoro únicamente es ser atesorado, por amor a la ostentación.

A medida que la tradición medieval de atesoramiento va cambiando, cambia también el carácter privado del tesoro o de lo coleccionado, y empieza a mutar, de nuevo, hacia una concepción de lo público. Por ello debemos detenernos brevemente en este cambio. Como hemos visto, el tesoro implica únicamente una relación de tenencia del objeto por motivos de ostentación y de atesoramiento. Sin embargo, Juan de Berry, príncipe francés de la dinastía Vaolis, constituye, para Julius Von Scholsser, el primer paso hacia una nueva forma de relación personal con los objetos poseídos, un caso que parece tener un pie en dos mundos, el del atesoramiento medieval y el del coleccionismo moderno, es decir, lo que más adelante se denominará "cámaras de maravillas". La innovación de Juan de Berry se centra, sobre todo, en tener motivos más profundos que sólo la ostentación para custodiar los objetos que posee, y una selección de los mismos por razones que no se limitan al gusto personal ${ }^{6}$. El primer rasgo moderno que se identifica en las colecciones privadas de los príncipes europeos de finales del siglo XV e inicios del XVI es fundamentalmente la pasión por la colección, lo cual implica una relación con el objeto distinta a la ostentación. Los objetos poseídos empiezan a tener una función que rompe con el atesoramiento por su valor en sí mismo. Vemos que los objetos, las reliquias, las rarezas y las maravillas ahora son valiosos porque tienen una significación estética e histórica. La mentalidad medieval empieza así a disolverse y el humanismo renacentista hace su aparición en degradé. Los lujos y las reliquias, pensadas hacia afuera, proyectadas hacia el exterior como símbolo de estatus social y riqueza, ya no son los únicos componentes de las colecciones, sino que empiezan a convivir con bibliotecas y pinturas, así como las curiosidades y rarezas.

Sin embargo, queremos detenernos en la expresión "en degradé". El humanismo no aparece de la noche a la mañana. De hecho, si vamos a los casos concretos, nos damos cuenta de que durante la primera mitad del siglo XVI este encuentra resistencias, puesto que en las colecciones predomina más un sentido de estatus social que el verdadero afán erudito humanista. En la Europa de inicios del Renacimiento el coleccionismo se va consolidando sobre todo como un fenómeno de clase, es decir que,

5 Julius Von Scholsser, Las cámaras artísticas y maravillosas del renacimiento tardío. Una contribución a la historia del coleccionismo (Madrid: Ediciones Akal, 1988).

$6 \quad$ Scholsser, Las cámaras artísticas. 38. 
además de las colecciones regias de reyes y príncipes, muchos aristócratas y nobles comienzan a intentar acercarse a la realeza por medio de una de las actividades a las que más tienen acceso, la adquisición de bienes muebles, de rarezas y de objetos suntuarios. "Otro hecho viene a sumarse al creciente desarrollo del coleccionismo, que cada vez gana más seguidores entre las clases pudientes que, no siempre alentadas por un interés intelectual, encuentran en el arte un producto cuya posesión les da prestigio y se convierte en exponente de su poder social"' . El uso que se le daba a los bienes y las razones que propiciaron su reunión no era medieval, pero tampoco humanista. Se basaba principalmente en el seguimiento de una moda extendida en casi toda la aristocracia y la nobleza europea.

Por un lado estaban quienes sólo buscaban la adecuación de sus interiores domésticos, sin otras pretensiones que la organización de un ajuar que cumpliese con sus necesidades funcionales y respondiera a los esquemas decorativos predominantes. $\mathrm{Y}$ después tenemos a los que de forma consciente pretendían seguir las modas e incorporarse a las nuevas constumbres sociales; sabedores de que estos usos eran pieza fundamental de los mecanismos de creación de imagen pública que tan necesarios resultaban para las estrategias de escalada y mantenimiento social ${ }^{8}$.

Así pues, no es raro encontrar de manera más frecuente las colecciones "prácticas" que las humanistas en la primera mitad del siglo XVI. La adecuación del interior doméstico como una colección de antigüedades, reliquias, rarezas y maravillas responde, de cierta manera, a un fenómeno de "escenografía doméstica", en donde la decoración interior de las casas de la nobleza estaba pensada como una réplica a escala de la ostentosidad de la corte, lo que reproducía el estatus de noble y suplía la necesidad de diferenciarse socialmente y de escalar socialmente. Y esto nos devuelve de nuevo al problema inicial: la pregunta por el carácter privado de la colección. Si estas nuevas colecciones cortesanas o aristocráticas, aún bajo una simple imitación de las colecciones reales, movidas bajo el seguimiento de una moda, están pensadas para ser ornamentales y para expresar estatus social, entonces son privadas en cuanto a la propiedad, pero pensadas "hacia afuera". Además, el carácter "expositivo" perdido durante los tesoros de las iglesias medievales se recupera en la medida en que los objetos poseídos tenían capacidad para suscitar deseo, evidenciado por el constante intercambio de regalos que implicaba una gran campaña de imagen, de "proyección social basada en el uso de la casa y sus ornamentos como armas de conformación ideológica".

Todo este recorrido que hemos hecho durante más de un siglo de lo que ha sido el coleccionismo en Europa tiene una desembocadura que se consolida en el ocaso

$7 \quad$ Serrano, La formación histórica del museo, 8.

8 Herrera, Coleccionismo y nobleza, 62.

$9 \quad$ Herrera, Coleccionismo y nobleza, 59. 
del siglo XVI: El coleccionismo ecléctico. Las cámaras de maravillas seguían consolidándose como el más claro antecedente de los actuales museos en la medida en que ordenaban coherentemente la exposición como un microcosmos, una reducción del universo, una reproducción a escala del mundo, compuesto tanto de "naturalia" como de objetos artificiales creados por mano del hombre. De esta manera, las cámaras de las maravillas o gabinetes de curiosidades (como el de Van Der Geest), en su concepción de microcosmos, dan paso a lo que denominamos el coleccionismo ecléctico: una combinación a menudo arbitraria de todas las formas de coleccionismo descritas antes, de propiedad privada, que trata de condensar un todo en una simple habitación abierta al público (accesible), con función de clase (pensada hacia afuera), pero también con un motor humanista (pensada hacia adentro). Aquí se combinaban las rarezas, las extravagancias, las obras de arte, las reliquias, la orfebrería, la recuperación de la antigüedad clásica, la escultura, la pintura, los retratos de hombres ilustres, los artefactos cartográficos y científicos, las bibliotecas, las armerías e incluso los objetos destinados al ocio y la diversión. "Aquí encuentran lugar todas las posibles rarezas y maravillas de la naturaleza, tanto las verdaderas como las imaginables, incluso los iusus naturae y los monstruos" 10 .

Poco a poco las cámaras de maravillas van a ir mutando hacia la galería de pinturas. Pero, en lo que nos interesa, es decir, en cuanto a la pregunta por el carácter privado de la colección, tienen unas características fundamentales. La cámara de maravillas está fundamentalmente pensada para la exposición al público, y por eso se constituye como la principal antesala de los museos. Sin embargo, aunque combina los tintes del coleccionismo humanista (es decir, pensado, no ornamental), en la mayoría de los casos el público no tiene un acceso a la colección más que como exhibición. Por eso encuentran similitudes importantes con el concepto de gabinete de curiosidades:

"Los gabinetes de curiosidades eran entendidos en el ámbito cortesano como un espacio para la evasión de las obligaciones que imponía al gobierno y la política a los monarcas, un lugar para su "recreación y divertimento". En ellos todo podía ser objeto de coleccionismo en una embriagadora mezcla de realidad y ficción, desde serpientes y cocodrilos disecados o fetos malformados, hasta "aletas de sirenas", frascos de "sangre de dragón" o "cuernos de unicornio", junto a antigüedades y reliquias. Coexistían los artificialia, esto es, objetos creados por la mano del hombre como obras de arte y antigüedades, con los naturalia, criaturas y objetos naturales, ya fueran ellos mismos, sus descripciones o sus imágenes dibujadas o pintadas" $"$.

Es decir, son espacios propiedad de los nobles y pensados para la recreación, aun con carácter expositivo y en cierta medida público. En contraste, a medida que se

10 Morán y Checa, El coleccionismo en España, 84.

11 Gutierez, Coleccionismo extravagante, 784. 
adentra el siglo XVII el gusto se va volviendo más artístico y deja de lado lo raro y lo curioso, aunque fuera un proceso largo y lento. Es difícil establecer una secuencia lineal del tránsito de las cámaras de maravillas a las galerías de pinturas, que pone de manifiesto una innovación en cuanto a la cámara de maravillas: las pinturas se venden y se compran. En este momento el carácter, digamos, "público", al menos en cuanto a la accesibilidad a la colección, toma un nuevo aire. Esto también está mediado por la importancia que tenían las pinturas a nivel diplomático. Sin embargo, no todo el mundo puede acceder a la colección noble de la España del siglo XVII. El gabinete de Van Deer Geest, por ejemplo, es una exposición abierta al público, tipo museo, pero él ejerce propiedad sobre los elementos de su colección. Por esta razón es que el concepto de coleccionismo privado es tan problemático.

Desde los mausoleos griegos hasta los gabinetes de pinturas, pasando por la concepción de "tesoros" medievales tanto religiosos como paganos, los casos híbridos como el de Berry, el coleccionismo ornamental de la aristocracia y su transformación en un coleccionismo "humanista" y finalmente el coleccionismo ecléctico tanto de las cámaras de maravillas como de los gabinetes de curiosidades (sin mencionar otras formas de disposición de los espacios como el studiolo italiano) evidenciamos que los conceptos de público y privado tienen un triple carácter: en cuanto a la propiedad, en cuanto al acceso y en cuanto a la intencionalidad (si está pensado "hacia adentro", es decir, para el deleite o desarrollo del espíritu personal del propietario, o "hacia afuera", es decir, para que sean vistos por los otros, ya sea bajo la lógica de la ostentación ornamental y la escalada social o la de lógica humanista). Será difícil encontrar un caso que sea privado en cada una de las tres dimensiones. No parece haber forma correcta de conciliar estos caracteres si no es creando una categoría propia en la que podamos enmarcar el Gabinete de Curiosidades de Van Deer Geest, y que hemos decidido llamar, de manera un poco arbitraria, "de mercader": privado en cuanto a la propiedad, público en cuanto al acceso, y pensado tanto hacia adentro (veremos que el gusto personal y el deleite artístico de Van Deer Geest fue fundamental al negarse a la compra de la Virgen de las Cerezas de Metsys por parte del mismo archiduque) como hacia afuera (se verá que el gabinete está pensado para transmitir al mundo un mensaje sobre la monarquía española).

\section{Las preocupaciones de un mercader de especias: "Gabinete de Curio- sidades de Cornelis Van Deer Geest" por Willem Van Haecht.}

En otra oportunidad hemos tenido la posibilidad de realizar un análisis iconográfico e iconológico con ojo microscópico de la pintura de Van Haecht, relacionando sus numerosos contenidos individuales con el contexto histórico en que se inserta la imagen, con la historia de la imagen misma, con otras pinturas del autor y con otras obras similares. Hemos podido reconocer buena parte de los elementos y las muchas referencias 
artísticas, científicas y políticas existentes. En este momento, sin embargo, no nos detendremos en los detalles, sino que trataremos de dar cuenta de las características del Gabinete como "Coleccionismo de Mercader" que acabamos de definir.

En primer lugar, uno de los elementos que más llaman la atención es el grupo de hombres estudiando con cuidado un globo terráqueo, en una zona de la habitación llena de artefactos de medición. No es en vano que estos artículos se encuentren allí pues, aunque no estemos en un modelo de studiolo, la ciencia sigue siendo una permanencia del coleccionismo del siglo anterior y sobre todo un símbolo importante del humanismo, que, ya lo hemos visto, se fundamenta sobre todo en el pensar la colección "hacia adentro", que tenga sentido erudito más que artístico. La colección de arte transmite un mensaje social en cuanto al buen gusto y al estatus del coleccionista (no en vano grandes personalidades están comprando en su gabinete), pero la presencia de un globo terráqueo y los instrumentos técnicos que permiten su estudio habla de su erudición. Este es tan solo uno de los elementos iconográficos que nos permiten definir esta doble vía, tanto hacia adentro como hacia afuera, del gabinete.

Pero junto con el carácter humanista del gabinete y su proyección hacia adentro coquetea el Hércules de Farnesio que se alza imponente en la puerta del recinto. Hércules ha sido un símbolo importante de la monarquía española sobre todo a partir de su dominación ultramarina. Las Columnas de Hércules, adoptadas como símbolo del imperio, se refieren a la extensión de su soberanía más allá del mundo conocido por el resto de Europa. El Hércules de Farnesio entra en relación directa no sólo con la presencia recreada de los archiduques representantes de la soberanía española sobre el territorio de los Países Bajos, sino también con la estatua que se ve afuera del recinto, una estatua de Carlos V que le dio el apodo de Kayser a la casa del coleccionista (sin mencionar el retrato del monarca en la parte superior de la pared). La pintura también tiene un tinte político que puede leerse en clave de agradecimiento o de homenaje a aquella Pax Hispánica que terminó de instaurarse en el territorio de los Países Bajos con la reconquista de este por parte de Alejandro Farnesio para el reinado de Felipe II luego de la rebelión de Francisco de Anjou. Sobre todo para el arte, el reinado de los Austrias fue especialmente benéfico. No es esta la primera vez que se representan a los archiduques visitando una galería en Amberes (Adriaen Van Stalbempt, las ciencias y las artes, versión de Baltimore, que difiere de la versión que se encuentra en el Museo del Prado, y en donde aparecen los archiduques): "Los archiduques eran la garantía de la Pax Hispánica en los territorios del norte. Durante su gobierno cesaron las guerras de religión y el catolicismo se consolidó. (...) Fueron los Habsburgo (Alberto era hijo de Rodolfo II e Isabel, la hija de Felipe II) quienes aseguraron el triunfo de la virtud sobre la ignorancia"12. Hay un claro mensaje político que se quiere transmitir al mundo, lo que denota una intención hacia afuera de la habitación misma.

12 Stoichita, La invención del cuadro, 28. 
Estas dos direcciones confluyen en uno de los sentidos iconológicos más interesantes: el referente a la técnica y la ciencia de la España del siglo XVII. Carlos Madrid Casado, en Un paseo cientifico por El Prado. La ciencia y la técnica en España entre los siglos XVI y XVIII a través de los cuadros del Museo del Prado, nos proporciona las claves para entender la presencia de artefactos científicos y de medición en el gabinete. Afirma que la contribución ibérica a la ciencia europea radicó fundamentalmente en las prácticas y técnicas orientadas hacia la náutica, la navegación y la cartografía. La ciencia y la técnica hicieron posible la grandeza del imperio, pues sin su respaldo ni España ni Portugal habrían podido llevar a cabo la descomunal expansión territorial, militar y administrativa del siglo XVI. Piénsese, por ejemplo, en la posibilidad de aplicar el tratado de Tordesillas sin un desarrollo considerable de la cartografía y la navegación. Por otro lado, debemos recalcar que durante el siglo XVII estaban desarrollándose en Europa los postulados de Francis Bacon y su inclinación por la técnica, las ciencias aplicadas y la experimentación; de manera que no es extraña la presencia de artefactos técnicos en los gabinetes, así como otros pintores (Goya o Velázquez) han hecho alegoría a la industria y a los gremios que se dedican a estas tareas. Es en los artefactos de cartografía y de medición del espacio en donde confluye el afán erudito (hacia adentro) con la reproducción del discurso imperial español (hacia afuera).

Otro elemento demuestra este doble sentido de la intencionalidad: la escena de la venta de la Virgen de las Cerezas de Metsys. En la escena se encuentra Van Der Geest con la mano en el corazón y con actitud melancólica. Tal como sucedió 13 años atrás (recordemos que la pintura es una recreación de la visita de los archiduques), el coleccionista se negó a otorgar la pintura de uno de los más grandes artistas de su tiempo anteponiendo su amor al arte antes que el favor de los gobernantes. La doble vía de la intencionalidad está explícita: es un recinto pensado hacia afuera, pues se constituye como un espacio de ventas (y al mismo tiempo como una exhibición), pero el deleite personal del coleccionista y el atesoramiento de los elementos coleccionados también hacen peso en la balanza. Por otro lado, el hecho de que Van Der Geest haya tenido la potestad de negarse a una venta habla también de la propiedad privada que ejercía sobre su gabinete y sus pinturas.

Sin embargo, los sentidos que ponen en tensión la intencionalidad de la colección de mercader vienen a resolverse cuando nos adentramos en el tema principal de la pintura y del gabinete en sí mismo: "el amor al arte", un discurso proyectado hacia adentro, motivado por los gustos o inclinaciones personales de Van Der Geest (y, hay que decirlo, de Van Haecht): el amor al arte. La negación a la venta de la obra de Metsys al archiduque es tan solo la primera parte de esta alegoría, que está alimentada por muchos otros símbolos. En las pinturas de las paredes encontramos los nombres de Rubens, Vranx, Noort, Seghers, Eyck, Metsys, Snyders y Wilden, todos grandes representantes de la pintura flamenca (y además la mayoría de ellos originarios de Amberes). A diferencia de otras colecciones de arte o galerías de retratos 
más variadas en cuanto a la procedencia de sus obras, el gabinete de Van Der Geest estaba exclusivamente pensado para albergar a los más grandes artistas y representantes de un género específico: el flamenco. La habitación puede pensarse entonces como un gran mausoleo específicamente diseñado para la conservación de la pintura flamenca, madre artística de Van Der Geest y de Van Haecht. No en vano, la pintura que el coleccionista se niega a perder es una de las más grandes obras de Mestsys, considerado fundador de la escuela flamenca. La híper-valoración del flamenco se hace más evidente cuando dirigimos nuestra mirada a la relación entre la pintura de Eyck Mujer en el baño y la estatua de Venus y Cupido, justo debajo de esta; la posición de ambos elementos es importante, como si quisiera darse a entender que la pintura flamenca está en condiciones incluso de competir con el arte clásico, algo muy curioso debido a la helenofilia del renacimiento. Hay más: el elemento que se encuentra en el punto central del gabinete, el grabado de Alejandro de visita en la casa de Apeles, trata de expresar que el gabinete mismo es lo que en la antigüedad hubiese sido el estudio de Apeles, el artista más famoso de su tiempo ${ }^{13}$.

Lo anterior se relaciona con otro símbolo importante: el blasón de Van Der Geest que se alza encima de la puerta, flanqueado por los bustos de Nerón y Séneca (maestro espiritual de Rubens y de muchos artistas flamencos) que representan la oposición entre la serenidad y la locura, y que consiste en una paloma extendiendo las alas sobre una calavera, representando el espíritu que vence sobre la muerte. En conjunto con los demás elementos que lo rodean (la inscripción Vive l'esprit que se entiende como viva el espíritu, las musas guardianas de la puerta), se revela el sentido total del gabinete y de la imagen, de coleccionar las obras de los más grandes artistas en un ejercicio de culto al arte y de su exacerbación con la necesidad de retratarlo. El amor al arte de Van Der Geest no se entiende sin su necesidad de mantener viva la memoria de aquello efímero en el tiempo por medio de la conservación y la exaltación de su legado: mantener viva la monarquía hispánica, mantener viva la tradición flamenca, mantener viva la tradición clásica, mantener vivo a Metsys cuyo centenario de su muerte se celebraba el mismo año en que Van Haecht pintó la obra y cuya obra maestra es protagonista de la escena. "Sobre la puerta de su gabinete, nos dice el arqueólogo Pierre Borel (1649), se hallaba una inscripción dirigida a los «entendidos» que presentaba a la colección como «Campos Elíseos donde los muertos resucitan en una necromancia lícita»" "14. Si este es el principal discurso de Van Der Geest, y responde casi exclusivamente a su gusto personal por el arte flamenco, ¿no predomina el discurso humanista, hacia adentro, sobre la intencionalidad hacia afuera?

13 "Apeles, el pintor más célebre de la Antigüedad, se había convertido en un segundo patrono, junto con San Lucas, de la cofradía de pintores en Amberes. La pintura se celebraba como Apellea Ars y los miembros de la cofradía se consideraban fieles y queridos discípulos de Apeles. Así, el grabado designa el espacio del gabinete como lugar de celebración de la Apellea Ars". Stoichita, La invención del cuadro, 240.

14 Stoichita, La invención del cuadro, 142. 


\section{La casa de España: El Alcázar de Madrid.}

Esta fuente en la que hemos centrado nuestro análisis hasta ahora, siempre ha estado enmarcada dentro de los límites del coleccionismo de mercader propio de los inicios del Siglo de Oro español, y lo hemos probado volviendo a un análisis iconográfico e iconológico de la pintura de Van Haecht. Pero, ¿Es el caso del mercader comparable con con otro tipo de colecciones, como las colecciones "regias" o reales? Trataremos de llevar a cabo esta comparación específicamente con la colección del "Rey de los coleccionistas" Felipe IV en el Alcázar de Madrid, que como veremos, bien pueden estar destinadas a otros propósitos, desarrollarse en ambientes físicos y situaciones personales muy distintas, y tener connotaciones simbólicas e iconográficas particulares, y no por ello diferir en el triple carácter de lo privado. Nos hemos acercado al inventario de $1636^{15}$ sobre el palacio y sus obras de arte, y hemos complementado su estudio con la revisión de otra fuente de gran utilidad: el tratado de arte más famoso del pintor y tratadista de la corte del mismo Felipe IV, Vicente Carducho en $1633^{16}$.

Felipe IV, al igual que su predecesor Felipe III, era famoso por ser un monarca más preocupado por el ocio y el tiempo libre que por la administración del imperio, por lo que delegaba funciones al aparato burocrático que desde Felipe II se había consolidado mientras que él se refugiaban en el arte, la danza, la música, la escultura y la pintura. El caso de Felipe IV es la exacerbación de esta tendencia, pues su afición por el coleccionismo es famosa por sí misma, y su colección del Alcázar se equiparó con las demás colecciones regias del resto de Europa ${ }^{17}$.

La importancia del Alcázar se resalta incluso más cuando tomamos en cuenta el hecho de que existen obras literarias, musicales y pictóricas de mano del mismo Rey, y toda su producción era guardada en este recinto ${ }^{18}$. Este monarca se caracterizó por ser un mecenas y un coleccionista insaciable, por promover las artes y las letras, la danza y el teatro al interior de la corte. Incluso las construcciones de otras residencias palaciegas pueden explicarse desde este punto de vista. De hecho, "Entre 1632 y 1639 toda la atención de la corte de Felipe IV estuvo centrada en las obras del Retiro. Pero a finales de la década, el interés por el nuevo edificio se enfrió rápidamente y los ojos del monarca volvieron a dirigir su mirada hacia el Alcázar" ${ }^{19}$. Su padre, Felipe III, ya había adecuado en cierta medida la residencia para convertirse en una colección, pero

\footnotetext{
$15 \quad$ Museo del Prado, Inventario del Alcázar de Madrid de 1636.

16 Vicente Carducho, Diálogos de la pintura (Madrid: Imprenta de Manuel Galiano, 1865). Esta edición del siglo XVIII es copia fiel de la original escrita de mano de Carducho en 1633.

17 Jorge Gómez Gómez, "La autoridad de Felipe IV a través del arte", en El universo simbólico del poder en el Siglo de Oro, Álvaro Baraibar y Mariela Insúa eds. (Nueva York/Pamplona: Instituto de Estudios Auriseculares/Servicio de publicaciones de la Universidad de Navarra, 2012), 115-116.

18 Gómez, La autoridad de Felipe IV, 113-114.

19 José Manuel Barbeito Díez, "Velázquez y la decoración escultórica del Alcázar", en: Velázquez, esculturas para el Alcázar, Real Academia de Bellas Artes de San Fernando ed. (Madrid, 2007) 113.
} 
Felipe IV inició su propio proyecto de colección en él, trayendo obras y esculturas de otros edificios ilustres como el Pardo (otro de los palacios de la familia real, que fue un sitio de recreo durante los Austrias y la residencia invernal del monarca durante los Borbones). Para las paredes del Alcázar se hicieron varias de las pinturas de la mano del mismo Velázquez, que consiguió el puesto de pintor de cámara gracias a su retrato de Felipe IV, a cuyo cargo estuvo la remodelación de 1940, y cuya carrera como pintor y restaurador se desarrolló en buena medida dentro de este edificio (su célebre "expulsión de los moriscos" también se pintó con el fin de contribuir a esta colección). Luego, "En 1628, la llegada de Rubens a Madrid dio un giro espectacular a la decoración de la estancia, pues el pintor vino ya con ocho cuadros destinados, por su formato y medidas, a ocupar los huecos libres en las paredes de la pieza" 20 .

Hemos identificado tres universos de sentido presentes en la colección del Alcázar, siempre coherentes con las indicaciones del tratado de Carducho. La primera y más extensa da cuenta de la predominancia de la intencionalidad proyectada "hacia afuera" del coleccionismo real al estar forzosamente condicionado por una dimensión estatal que no poseía el coleccionismo de mercader. La otra sección permite apreciar que, aunque haya predominancia de una intencionalidad hacia afuera, el capricho y el gusto personal no están completamente vetados.

\section{- Patrocinio: el palacio como espacio de propaganda política}

En primer lugar nos centraremos en el que hemos considerado "propaganda política", que en términos de Rebollo sería "de patrocinio" 21 , que son zonas que suelen estar destinadas al uso público y la exposición.

Empezamos en el Jardín de los Emperadores, espacio que guarda una coherencia temática bastante compacta: estaba destinado a albergar las estatuas de grandes emperadores romanos: Julio cesar, Augusto Cesar, Tiberio Cesar, Tiberio Claudio, César Augusto, Claudio Augusto, Vespasiano, Dominico e incluso el mismo Nerón ocupa un lugar en medio de esta colección de esculturas, entre algunas otras. Todas, además, guardan características similares: suelen ser bustos, estatuas desde las rodillas o del medio cuerpo para arriba (pocas, en realidad, son estatuas de cuerpo completo), todas de mármol blanco y bien conservadas. Hay una estatua, sin embargo, que guarda un lugar especial: Carlos I de España, emperador del Sacro Imperio Romano Germánico bajo el nombre de Carlos V, apodado "El César". El jardín de los emperadores no es una recuperación del esplendor del imperio romano por simple gusto, recodemos que fue Carlos V quien intentó por primera vez llevar la capital imperial a Madrid y establecer en el Alcázar la sede de la corte y la residencia real (un proceso más o

$20 \quad$ Barbeito, Velázquez y la decoración, 113.

21 Ángel Rodríguez Rebollo, "Felipe IV, Velázquez y el Alcázar de Madrid. Recapitulación y nuevas vías de estudio a través del coleccionismo regio", en Goya, No. 395, 2017. 
menos truncado por sus continuas guerras y viajes a Europa), y que para entonces su Imperio era verdaderamente mundial, pues no solo se extendía al otro lado del atlántico hasta las Indias, y cruzando estas, al otro lado del pacífico, sino que además a su jurisdicción pertenecían territorios en el centro de Europa y en Italia, mientras que al mismo tiempo bajo su corona se unificaba el antiguo Imperio Romano-Germánico, que incluso tuvo el poder militar y simbólico de invadir Roma, saquearla y poner prisionero al mismísimo Papa en su propio castillo. Y así como en su momento el Imperio Romano dominó la totalidad del mundo civilizado (tanto así que el muro de Adriano, en el extremo norte del imperio, para entonces era realmente el límite del mundo), España hizo lo propio siglos después. El jardín de los emperadores parece estar dedicado única y exclusivamente al emperador, pues en él no tienen cabida los tres Felipes que le sucedieron. Sólo Carlos V eral el verdadero César y estaba la altura de tan distinguidos regentes.

Por otro lado, la connotación simbólica del Jardín de los Emperadores toma mayor relevancia cuando tenemos en cuenta que era un lugar "público", más frecuentado por los invitados al palacio, la corte y los embajadores que por el mismo monarca. La decoración de las habitaciones y los espacios siempre debe distinguir entre el uso que se le da y lo estableció Carducho en su tratado: "Y siempre que se ofrezca adornar alguna fábrica, se debe atender a la calidad della en general, y el uso de cada parte en particular, y la persona que le ha de ocupar y manda hacer"22. Así, y de aquí en adelante, siempre debe distinguirse, entre espacios públicos y privados, los usos que se daban: residencia, salón de reuniones, de exposición, de asuntos de gobierno. En este caso, el jardín estaba pensado para la exposición de la corte y de los embajadores que llegaran al palacio, para hacer crecer en ellos el sentimiento, por medio de la representación visual, de que tenían el privilegio de estar ante el verdadero Imperio Romano, cuya recuperación sólo fue posible en manos españolas y fracasó en manos de tantas otras naciones y monarquías.

Otras dos zonas importantes dentro del contexto del "patrocinio" son el "Salón Grande de las Fiestas Públicas" y la "Pieza Nueva sobre el zaguán y puerta principal del palacio". Ambas habitaciones han llamado nuestra atención debido a su explícito carácter público, únicamente destinadas a la exposición ante la corte y los invitados al palacio. En el "Salón Grande de las fiestas públicas" encontramos muchos lienzos con ciudades de España, Italia y Francia, entre las cuales vemos la Ciudad de Granada (tomada por los moriscos), Nápoles, Burgos, Zaragoza, entre muchas otras. Además, varios lienzos de las guerras del emperador Carlos V, la entrada de Felipe II a Lisboa, la batalla en Málaga, la entrada de Felipe II en la Coruña y fiestas al mismo en Valladolid, e incluso un total de 12 lienzos que representan las batallas de Carlos V en Alemania. A esto se suman varias representaciones de celebraciones (como las fiestas del papagayo 
en Flandes) y una descripción de la villa de Madrid, además de algunas alegorías a grandes virtudes. Sin duda el factor predominante en esta sala son las ciudades que pertenecen a la corona española, como si se tratara de exponer a los asistentes a las fiestas qué conforma el reino del que hacen parte, una especie de clase de geografía pictórica diciendo: "así de grande es nuestro imperio, y así lo hemos conquistado".

Por otro lado, la "Pieza Nueva" es la que luego de las remodelaciones de Velázquez en 1640 se convertiría en el "Salón de los Espejos", el más iconográficamente denso, el más famoso e importante, aquel que parecía representar el corazón de la monarquía y al que solo los más ilustres personajes tenían acceso, también tiene una carga propagandística potente. Luego de su remodelación, el Salón de los Espejos se convirtió en el más famoso e importante del recinto, junto con la Sala Ochavada, que, como se verá, en el inventario de 1636 aún estaba ocupado por algunas mesas y cuadros y le faltaba el carácter iconográfico que le luego le otorgó Velázquez. Éste se esforzó por darle una connotación política muy potente a la colección de estas dos salas en específico: "sobre el dintel de acceso al Salón de los Espejos desde la Pieza Ochavada se situó el Hércules matando al león de Nemea de Rubens como prevención a los extranjeros que se disponían a cruzar hacia el corazón simbólico de la monarquía hispánica"23. La razón por la que nos hemos detenido en referenciar lo que significó el Salón de los Espejos en épocas posteriores es porque antes de la remodelación ya existía esta importancia regia que lo hacía una de las habitaciones más valiosas del palacio, sobre todo en lo que tiene que ver con la recepción de embajadas extranjeras y exóticas, que también debían pasar por este "trayecto ceremonial" a lo largo de muchas habitaciones y pasillos especialmente dispuestos para la ocasión ${ }^{24}$. Esto nos habla del hecho de que, incluso en los lugares más reservados y de accesibilidad limitada, el discurso proyectado "hacia afuera" era el más importante.

Así pues, en la Pieza Nueva se encontraban, además de la "expulsión de los moriscos" de Rubens, un retrato del emperador Carlos V armado y a caballo, unos retratos de las cuatro furias (Sísifo y Tántalo de Ticiano, y Ixion y Ticio de Alonso Sánchez), "otro lienzo grande con moldura dorada y negra, en que está pintado al olio de mano del Ticiano, el señor Rey Phelipe II en pie y armado, que está ofreciendo al príncipe don Diego y un ángel en lo alto que le da una palma con un letrero que dice "maior est tibi" y en lejos la batalla naval y un turco cautivo con empresas de rendimiento" 25 , la conjuración que hizo Escipión a los romanos de mano de Vicencio

23 Lucía Rodríguez Navarro, "Reseña: El inventario del Alcázar de Madrid de 1666. Felipe IV y su colección artística", En Librosdelacorte.es, $n^{\circ} 13$, año 8 (2016). Recurrimos a la reseña que ha hecho Lucía Navarro, de la Universidad Autónoma de Madrid, debido a la imposibilidad logística de acceder al libro reseñado por ella: Gloria Leiva Martínez y Ángel Rodríguez Rebollo, El inventario del Alcázar de Madrid de 1666. Felipe IV y su colección artística (Madrid: Ediciones Polifemo, 2016).

24 Rubén López Conde, "Escenarios de poder: la monarquía hispánica y la recepción de embajadas exóticas en el siglo XVII", en Goya, No. 363, P. 126-141, 2018. 132-133.

$25 \quad$ Museo del Prado, Inventario del Alcázar de Madrid de 1636. 
Carducho, la reconciliación de Jacob y Saul de Rubens, un retrato de Felipe IV de Rubens, una pintura de la reina Sabaa ofreciendo sus tesoros al rey salomón de mano del pintor romano Guido Bolones (hasta aquí el componente "diplomático de las pinturas es muy fuerte).

Todo lo anterior, además, va completamente acorde a las premisas de Carducho:

Si fueren galerías Reales, sean historias las que se pintares, graves, majestuosas, ejemplares y dignas de imitar, como son premios que grandes Monarcas han dado a los constantes en el valor, y en la virtud, castigos justos en maldades y traiciones, hechos de Héroes ilustres, hazañas de los más célebres Príncipes y Capitanes, triunfos, victorias y batallas. Scipion contra Anibal, Eneas contra Turno, César contra Pompeyo, Xerxes contra los Lacedemonios, y otros semejantes: y en las modernas entre tantas que hay, las de los Cárlos el Magno, y el César, cuyas victorias fueron excelsas, y sus batallas poderosas: y si acaso tal vez conviniere, o fuere gusto del dueño, pintar las obras de Virgilio, Homero, y las fábulas de Ovidio, procure demostrar con afecto y propiedad, la moralidad virtuosa que encierra en sí, oculta a la ignorancia, y no la corteza incasta, y descompuesta, atendiendo al provecho, no solicitando el daño ${ }^{26}$.

Sin embargo, otro mundo de significado, además de la recuperación de la legitimidad imperial romana del Jardín de los Emperadores y de la función casi "educativa" de la decoración de las salas públicas para representar a España y su grandeza, es la coyuntura política por la que atravesaba el imperio que tiene repercusiones en la colección. Es el caso de la Galería del Cierzo. Siendo el Cierzo otro espacio público y destinado a los cortesanos, el mensaje es de legitimación: además de contener dos vistas a Lisboa representando seguramente la entrada de Felipe II a esa ciudad, en la Galería se encuentran la gran mayoría de retratos de los soberanos portugueses miembros de la casa de Austria, lo cual tiene gran sentido si se tiene en cuenta que el inventario está redactado en momentos políticamente convulsos para Portugal, unos años antes de su separación de la Corona española en 1640, por lo que la galería podría interpretarse como un pequeño intento simbólico de legitimación de la soberanía española en el extremo occidental de la Península.

El imponente lienzo que representaba la llegada de les ejércitos de Felipe II a Lisboa, colgado en 1636 en el otro gran espacio público, el Salón Dorado o de Comedias; la portada del libro de Caramuel; y una pintura de Pietro del Po, la Apoteosis de la Virgen con Felipe IV (Toledo, catedral), esta última realizada no ya en España sino en Roma hacia 1662 y donde aún se reivindicaba, desde el palacio de la Embajada española ante la Santa Sede, la pertenencia a la corona hispana del reino de Portugal ${ }^{27}$.

$26 \quad$ Carducho, Diálogos con la pintura, 246.

27 Rebollo, Felipe IV, Velázquez y el Alcázar de Madrid, 96. 


\section{- Zonas de lo privado y el gusto personal}

Sin embargo, tengamos de nuevo en cuenta que el palacio, además de ser sede de la corte y de servir para la recepción de embajadas, también era la residencia real, en donde el monarca pasaba buena parte de sus días y de su rutina diaria. Los espacios privados tienen, por tanto, otras connotaciones distintas. El "Aposento de las Furias, donde duerme su Magestad", contiene varios retratos de la familia real directamente relacionada con Felipe IV (las rivalidades entre monarquías, por ejemplo, no aplican en esta habitación, pues la Casa de Austria tenía representantes en Inglaterra y Francia, con las que España no tenía las mejores relaciones, y aun así aparecen retratados monarcas franceses e ingleses. Más importante aún es la presencia de la ascendencia de la casa Austria, sirviendo de alguna manera como legitimidad a la Corona que porta Felipe IV ${ }^{28}$. Otras obras acompañan estos aposentos seguramente con motivaciones que se inclinan más hacia el gusto personal del coleccionista que a la propaganda política o la legitimidad. El caso de la presencia de la pintura de Rubens Vertumno y Pomona (que en sus sucesivos traslados siempre se mantuvo en áreas privadas como la Torre de la Reina o la Pieza donde Cenaba su Magestad) en el despacho de su Majestad donde compartía pared con Las Meninas, muestra perfectamente la influencia del gusto privado del monarca:

Era el cuarto más íntimo y entrañable del monarca. Posiblemente el lienzo ocupó un lugar central en uno de los muros del despacho, pues es uno de los cuatro de mayores dimensiones de los veintiséis que allí se encontraban. Los restantes son alegorías, flores y bodegones, tanto de maestros italianos como flamencos, típicos del gusto ecléctico de Felipe IV. Las pinturas están seleccionadas con intencionalidad clara, que no he visto haya sido considerada. Vemos una recreación amable en la belleza y el amor. Todo acorde con la armonía y buen gusto de la decoración de unas estancias donde Velazquez tuvo una directa implicación. Ninguna pintura religiosa cubre los muros de este despacho que preside Apolo en la bóveda ${ }^{29}$.

La vida personal del monarca también tiene implicaciones tanto en la decoración como en la disposición del espacio, como lo demuestra la conversión de la Pieza de los Trucos en la futura Sala Ochavada, más simbólica y menos práctica, dedicada al consuelo de un monarca que acababa de perder a su hijo.

28 "En el aposento del rey, por ejemplo, la llamada Pieza de las Furias, se situaban los famosos cuatro condenados de Tiziano, además de decorar el friso superior la serie de reyes asturleoneses que, comenzando con Pelayo y Favila y culminando con los retratos de Felipe III y Felipe IV, tenían la función de velar el sueño del monarca y constituían una forma de justificación del derecho al trono". Rodríguez, Reseña: el inventario del Alcázar.

29 Matías Díaz Padrón, "El Lienzo de Vertumno y Pomona de Rubens en el cuarto bajo de verano del Alcáza de Madrid”, Archivo Español de Arte, Vol. 73, No. 291, p. 268-277 (2000): 276. 
Otra zona privada importante era el oratorio, que contenía pinturas del Eccehomo de Ticiano, lo cual concuerda con las recomendaciones de Carducho: "porque si es Templo, Claustro, ó Oratorio, claro está que todo cuanto se ha de pintar en su uso y adorno, serán historias de la vida, y muerte de nuestro Señor Iesu Christo, de su Santísima Madre, y de santos que están gozando y asistiendo a Dios en aquella beatifica morada celestial. Háse de atender a la advocación de la Iglesia, y devoción del Patron." ${ }^{30}$. Por su lado, Carducho no dice nada acerca de los espacios de recogimiento y estudio, como la Librería del palacio, pero sí podemos encontrar factores comunes con los "espacios de estudio" del coleccionismo burgués de Van Der Gest: en la torre que sube a la librería habían "diez y siete mapas, sobre papel, iluminadas, de mano de Don Pedro de Texeida, que tienen de largo menos de bara, que son de diferentes ciudades y puertos de España, Francia y Italia que se mudaron de la galería del cierzo aquí" ${ }^{11}$, y una vez dentro de la habitación abundaban las mesas, relojes, cuadrantes y otros muebles, junto con estatuas de pequeño tamaño, medallas y otros objetos de decoración mueble: al igual que el coleccionista de Amberes, un espacio menos pomposo y más dedicado al conocimiento y el estudio, pero a diferencia del mismo, separado (de hecho, en una torre) del resto de la colección.

\section{A manera de conclusión: La recuperación del contexto}

A lo largo de esta exposición hemos dado cuenta de que, definitivamente, la colección del Alcázar de Madrid de 1636 no es una colección de exposición como la de Van Deer Gest, es una colección "de acompañamiento" a la vida privada del rey y al mismo tiempo a las acciones de gobierno. La naturaleza del recinto tiene implicaciones directas en la manera de coleccionar, pues mientras que el Gabinete de Van Der Geest es una única habitación destinada exclusivamente a la exposición, en el palacio real confluía la vida privada del rey, su corte, las embajadas extranjeras, sus reuniones de gobierno, sus espacios de recogimiento, etc. El único espacio que parecía estar destinado a los quehaceres de la vida diaria en el gabinete de Van Deer Geest era el escritorio que nos llevó a hablar del Studiolo italiano. A diferencia de esto, la gran cantidad de utilidades del Alcázar le dan a la colección regia una diversidad difícil de comprimir en estas páginas, y por tanto, hacen aparecer nuevos "universos de significado" que explican por qué está allí tal pintura o escultura y no otra: la reivindicación del Imperio Romano, la propaganda de la grandeza de España, la legitimidad de su soberanía, la religiosidad, el estudio, la vida personal del monarca, el tratado de arte más célebre de la época.

Lo que sí podemos afirmar con seguridad es que no todos los espacios del Alcázar están destinados al mismo coleccionismo que practicaba Van Der Geest, es decir,

$30 \quad$ Carducho, Diálogos con la pintura, 245.

31 Museo del Prado, Inventario del Alcázar de Madrid de 1666. 
del arte por el arte, de la intencionalidad "hacia adentro". Más bien están, en buena medida, atravesados por la naturaleza del palacio como baluarte de la monarquía. Sin embargo:

Aunque en muchos de esos casos la decoración fue encargada expresamente, y no pertenecen al ámbito estricto del coleccionismo sino del patrocinio (en la medida en que se puedan diferenciar claramente ambos), en otros (especialmente las Bóvedas de Tiziano, y el Salón de los Espejos) sí se trata de un coleccionismo de pinturas, y del aprecio de éstas no sólo en razón de sus cualidades representativas sino también estéticas e, incluso, histórico-artísticas ${ }^{32}$.

Van Der Geest, si bien combinó una intencionalidad hacia adentro y hacia afuera, es dudoso que el tema principal de su gabinete, es decir, mantener viva la memoria de los maestros flamencos, sea fácilmente reconocible como discurso por los visitantes a su exposición, porque está más relacionada a su gusto personal. La colección de Felipe IV, por el contrario, no ofrece inclinaciones por un tipo de pintura u otro, porque en realidad su objetivo no tiene que ver mucho con el arte por el arte, sino con la reivindicación de la monarquía y la exaltación de su propia persona y su familia. Sin embargo, vemos que los papeles, de alguna manera, se invierten. Mientras que en el gabinete de Amberes la monarquía es importante para el arte, en el palacio de Madrid el arte es importante para la monarquía. Las herramientas de que se sirve cada uno de estos están representadas en el contrario: la monarquía es valiosa para Van Deer Geest porque gracias a ella y a su protección el arte flamenco logró florecer y él pudo enamorarse de las obras que alberga en su colección; mientras tanto, la monarquía se vale del arte para autolegitimarse y para llevar a cabo una labor de patrocinio como lo fue, seguramente, la protección al arte flamenco. Cada uno es la salvación del otro. Hoy en día podemos afirmar con seguridad que el siglo XVII español no se entiende sin el arte, y el arte flamenco no se entiende sin la monarquía. Su relación es espiral.

\section{Bibliografía}

Barbeito Díez, José Manuel. "Velázquez y la decoración escultórica del Alcázar". Velázquez, esculturas para el Alcázar, Real Academia de Bellas Artes de San Fernando (2007).

Carducho, Vicente. Diálogos de la pintura. Madrid: Imprenta de Manuel Galiano, 1865.

Castán, Alberto y Delia Sagaste. Todo lo raro y hermoso. Las «cámaras de maravi-

32 Javier Portús (2012), El concepto de Pintura Española: Historia de un problema, (Madrid: Editorial Verbum), 62 . 
llas», pervivencia estética y museografía del modelo.

Checa Cremades, Fernando. "El Marqués del Carpio (1629-1687) y la pintura veneciana del Renacimiento. Negociaciones de Antonio Saurer". Annales de Historia del Arte, 14, 193-211 (2004).

------- y Miguel Morán. El coleccionismo en España: de la cámara de maravillas a la galería de pinturas. Madrid: Ediciones Cátedra, 1985.

Díaz Padrón, Matías. "El Lienzo de Vertumno y Pomona de Rubens en el cuarto bajo de verano del Alcáza de Madrid". Archivo Español de Arte, Vol. 73, No. 291, (2000). p. 268-277.

García Serrano, Federico. "La formación histórica del concepto de museo". El museo imaginado, Base de datos y museo virtual de la pintura española fuera de España, Federico García Serrano. Madrid, 2000.

Gómez Gómez, Jorge. "La autoridad de Felipe IV a través del arte". El universo simbólico del poder en el Siglo de Oro, Álvaro Baraibar y Mariela Insúa eds. (Nueva York/Pamplona: Instituto de Estudios Auriseculares/Servicio de publicaciones de la Universidad de Navarra, 2012).

Gutierez Pla, Coro. Coleccionismo extravagante: "monstruos", “fenómenos", "portentos" y sus imágenes en las cortes de la Edad Moderna. II Encuentro de jóvenes investigadores en Historia Moderna. Lineas recientes de investigación en Historia Moderna, Félix Labrador Arroyo ed. (Universidad Rey San Carlos: Ediciones Sinca, 2015) [783-801].

Leiva Martínez, Gloria y Ángel Rodríguez Rebollo. El inventario del Alcázar de Madrid de 1666. Felipe IV y su colección artística. Madrid: Ediciones Polifemo, 2016.

López Conde, Rubén. "Escenarios de poder: la monarquía hispánica y la recepción de embajadas exóticas en el siglo XVII”. Goya, No. 363 (2018).

Martínez Leiva, Gloria y Ángel Rodríguez Rebollo. Quadros y otras cosas que tiene Su Magestad en este Alcázar de Madrid. Año de 1636. Madrid: Fundación Universitaria Española, 2007.

Peterson, Charles. "The Five Senses in Willem II van Haecht's Cabinet of Cornelis van Der Geest”. Intellectual History Review. 20:1 (2010): 103-121, https://doi. 
org/10.1080/17496971003638274

Museo del Prado, "Inventario del Alcázar de Madrid de 1636", en: Inventarios reales: Real Museo (1834); Palacio de San Ildefonso (1814); Palacio del Real Sitio de Aranjuez (1818); Real Palacio de Madrid (1814), Vol. 12. Disponible en: https://www.museodelprado.es/aprende/biblioteca/biblioteca-digital/fondo/inventarios-reales-v12-real-museo-1834-palacio-de/3e5218fb-3639-432b-be13$9 \mathrm{a} 7295423901$

Pastor, Don Luis. Iconología o tratado de alegorías y emblemas, Tomo I. México: Imprenta económica, 1986.

Phillipe, Blom. El coleccionista apasionado, una historia intima. Barcelona: Editorial Anagrama, 2001.

Portús, Javier. El concepto de Pintura Española: Historia de un problema. Madrid: Editorial Verbum, 2012.

Rodríguez Navarro, Lucía. "Reseña: El inventario del Alcázar de Madrid de 1666. Felipe IV y su colección artística", En: Librosdelacorte.es, $\mathrm{n}^{\circ} 13$, año 8 (otoño-invierno 2016).

Rodríguez Rebollo, Ángel. "Felipe IV, Velázquez y el Alcázar de Madrid. Recapitulación y nuevas vías de estudio a través del coleccionismo regio". Goya, No. $395,2017$.

Stoichita, Victor. La invención del cuadro. Arte, artifices y artificios en los orígenes de la pintura europea. Barcelona: Ediciones de Serbal, 2000.

Ureña Useda, Alfredo. "La pintura andaluza en el coleccionismo de los siglos XVII y XVIII". Cuadernos de Arte e iconografía, no 13 (1998): 99-148.

Urquízar Herrera, Antonio. Coleccionismo y nobleza. Símbolos de distinción social en la Andalucía del renacimiento Madrid: Marcial Pons Historia, 2007.

Von Scholsser, Julius. Las cámaras artísticas y maravillosas del renacimiento tardio. Una contribución a la historia del coleccionismo. Madrid: Ediciones Akal, 1988. 